\title{
Damage tolerance of cold drawn ferritic-austenitic stainless steels wires for prestressed concrete
}

\author{
Andrés Valiente, Mihaela Iordachescu*
}

\begin{abstract}
A B S T R A C T
Damage tolerance of high strength cold-drawn ferritic-austenitic stainless steel wires is assessed by means of tensile fracture tests of cracked wires. The fatigue crack is transversally propagated from the wire surface. The damage tolerance curve of the wires results from the empirical failure load when given as a function of crack depth. As a consequence of cold drawing, the wire microstructure is orientated along its longitudinal axis and anisotropic fracture behaviour is found at macrostructural level at the tensile failure of the cracked specimens. An in situ optical technique known as video image correlation VIC2D is used to get an insight into this failure mechanism by tensile testing transversally fatigue cracked plane specimens extracted from the cold-drawn wires. Finally, the experimentally obtained damage tolerance curve of the cold-drawn ferritic-austenitic stainless steel wires is compared with that of an elementary plastic collapse model and existing data of two types of high strength eutectoid steel currently used as prestressing steel for concrete.
\end{abstract}

\section{Introduction}

Austenitic and ferritic-austenitic stainless structural steel used as concrete reinforcement has been recently raised worldwide $[1,2]$. These stainless steel reinforcements are offering a good combination of strength, toughness, and high ductility, together with long term resistance to the corrosive attack of aggressive environments, including the concrete in which the rebar is buried [3,4]. Such a performance of stainless steel as concrete reinforcement invites to explore its use as prestressing steel, provided that it can be endowed with the required strength. Cold drawing is a technique suitable for this purpose to the point that today almost all the prestressing steel used in concrete structures is cold drawn eutectoid steel.

Recently published investigations confirm that ferritic-austenitic stainless steel preserves its low susceptibility to the stress corrosion cracking and hydrogen embrittlement when converted to a high strength wire $[3,5]$ by cold drawing. These results justify the interest of assessing those aspects of the mechanical behaviour of cold drawn stainless steel wires concerning their use as active reinforcement for concrete prestressing. In particular, the effect of cold working on ductility of stainless steel [6-8], which, when compared with the requirements of the prestressing steel standards [9], might involve unacceptable damage tolerance levels. Thus, the potential use of the cold drawn ferritic-austenitic stainless steel as prestressing steel requires the damage tolerance assessment and its comparison with equivalent data of currently used prestressing steels.

In this view, the paper applies a simple procedure for assessing the damage tolerance of a cold-drawn ferritic-austenitic stainless steel based on fracture tests of cracked wires, with surface cracks propagated by fatigue perpendicularly to the wire longitudinal axis. Since cracks are the most dangerous type of damage, the curve resulting from plotting the failure load as a function of crack depth is a quantitative empirical indicator of the wires damage tolerance. 
Afterwards, the damage tolerance assessment is enhanced by comparing experimental values with the results of applying an elementary plastic collapse model for transversally cracked tensile bars [10] and existing data of two types of high strength eutectoid steel [10-12].

The tested wires steel is a noncommercial product manufactured using industrial procedures. Its high level of cold drawing produces a strongly orientated microstructure along the drawing direction. This induces anisotropic fracture resistance and influences the failure mechanisms of the tested wires. Thus, an in situ optical technique known as video image correlation, VIC-2D [13], was additionally used to get an insight into the tensile failure mechanisms exhibited by the cracked wires at macrostructural level.

\section{Experimental details}

The chemical composition of the ferritic-austenitic stainless steel cold-drawn wire, of $4 \mathrm{~mm}$ diameter, used in this investigation, corresponding to the EN 1.4462 grade duplex, and usually referred as 2205 [14,15], is presented in Table 1. A $9 \mathrm{~mm}$ diameter bar, in mill-annealed condition, equivalent to full annealing with some cold work, was used as base metal for cold drawing in several passes the wire.

To assess the cold-drawing effect on the wire microstructure, standard procedures were used to prepare metallographic specimens. The wire and also the bar microstructures were analysed on longitudinal and transverse axis directions by optical microscopy after previous polishing and selective etching with aqua regia and Beraha reagents [16].

Tensile properties at room temperature were determined by testing $250 \mathrm{~mm}$ length wires and bars. The tests were performed with a $200 \mathrm{kN}$ servohydraulic universal testing machine using a constant crosshead speed of $1 \mathrm{~mm} / \mathrm{min}$. Elongations were measured on a gauge length of $25 \mathrm{~mm}$ with a conventional clip-on extensometer. Besides the wire and bar specimens, the flat specimen shown in Fig. 1 was also used for tensile characterisation of the wire steel. In this case, the only difference in the testing conditions was the substitution of the clip-on extensometer with a "virtual extensometer" provided by the in situ optical system VIC-2D. The test was mainly used as a baseline for the optical technique adjustment for its future usage in fracture tests.

VIC-2D is a displacement and strain measurement technique capable to analyse the digital images taken by a fixed camera during tensioning of a flat specimen. The camera is placed perpendicular to the specimen surface and takes consecutive digital images at a given rate. The images are used to monitor the changes of a speckle pattern, previously applied on the specimen surface. The system calibration requires only the determination of the scale factor of the acquired images. The system uses an iterative spatial domain cross-correlation algorithm to track the speckle pattern movement during loading; the Lagrangian displacement field over a plane 2D area of interest (AOI) is computed and recorded for each image. Thus, the dedicated software of VIC-2D transforms the AOI into a field-sequential arrangement of points wherein virtual clip-on extensometers of any gauge length can provide elongation data. The load corresponding to each instant image results by synchronizing the time sequence of the testing machine with that of VIC-2D.

The fracture tests designed to assess the damage tolerance require fatigue precracking of the $250 \mathrm{~mm}$ long wires, used as specimens. To initiate the crack growth, sharp notches, of $0.5 \mathrm{~mm}$ depth, were machined with a straight front perpendicular to the longitudinal axis of the wire. Fatigue precracking was performed at room temperature by applying cyclic tensile loads initially ranging between 1 and $4 \mathrm{kN}$; as the crack grew, the maximum of this range was gradually decreased to values well below the plastic collapse load of the cracked cross-section. A conventional clip-on extensometer, of $12.5 \mathrm{~mm}$ gauge length, capturing the notched zone, was used for monitoring the crack growth through the specimen elastic compliance. The average number of cyclic loadings applied on each specimen was of $10,000 \mathrm{cy}-$ cles, at a frequency of $5 \mathrm{~Hz}$. Nine wire specimens were fatigue pre-cracked for the damage tolerance tests. Other three wires were fatigue pre-cracked and converted to plane specimens on a length of $25 \mathrm{~mm}$, as shown in Fig. $2 \mathrm{~b}$ and $\mathrm{c}$. To obtain the record of the fracture mechanisms these specimens were tensile tested up to fracture using the VIC-2D system.

The fracture tests of the cracked wires and cracked flat specimens were performed according to the already described tensile tests procedure.

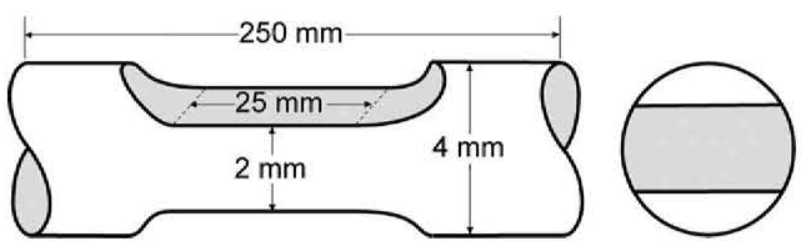

Fig. 1. Sketch of flat specimen used for tensile testing the cold-drawn material; specimen geometry with dimensions in $\mathrm{mm}$.

\section{Experimental results}

\subsection{Microstructure and mechanical characterisation}

As shown in Fig. 3a and b the microstructure of the tested 1.4462 duplex stainless steel before cold drawing (the $9 \mathrm{~mm}$ diameter bar) is morphologically anisotropic, as the steel constitutive phases are still markedly oriented in the rolling direction, even after annealing. Ferrite is the dominant texture component (Fig. 3a), despite that the spreading of austenite is quite large. The steel microstructure after cold drawing (the $4 \mathrm{~mm}$ diameter wire) consists of ferrite and austenite of lamellar morphology, both highly elongated in the drawing direction and having almost identical volume fractions (Fig. $3 \mathrm{c}$ and d). Comparison of Fig. $3 \mathrm{~b}$ and $\mathrm{d}$ shows the high grain refinement produced by cold drawing on the wire cross-section.

The cold drawing effect at microstructure level is accompanied by important changes of tensile properties, as results from Table 2 . This effect can be also seen in the engineering stress-strain curves presented in Fig. 4, together with images of broken specimens. The 1.4462 duplex stainless steel shows higher ductility and lower yield strength before cold drawing. The heavy cold deformation induced by manufacturing highly increases the yield and tensile strengths and reduces ductility, by strain hardening [6-8]. The measured maximum uniform elongation of the wire, of $2.2 \%$, indicates a poor remaining strain hardening capacity of the cold deformed microstructure, lower than that of 3.5\% required for a eutectoid prestressing steel [9].

The flat specimens were tested with the VIC-2D optical technique to check its reliability when comparing with the displacement data provided by the conventional clip-on extensometers used with the wire specimens. No information on the gradual decrease of load beyond the tensile strength could be captured with the conventional clip-on extensometer. On the contrary such information could be obtained in case of flat specimens using the virtual extensometer which can capture the entire gauge length where necking can occur. The results showed enough confidence to the optical technique usage for getting an insight into the mechanism of tensile failure of plane cracked specimens extracted from the cold-drawn material.

\subsection{Fracture analysis}

According to the macrofractographs obtained after the wire fracture the fatigue crack propagation took place in mode I, along the symmetry plane of the starting notch (Fig. 5b). A semi-elliptical crack configuration (Fig. 5a) with its centre located at the periphery of the wire was considered for the analysis of the fatigue

Table 1

Chemical composition of the tested 1.4462 duplex steel (weight percentage).

\begin{tabular}{|c|c|c|c|c|c|c|c|c|c|c|}
\hline & C & $\mathrm{Si}$ & $\mathrm{Mn}$ & $P_{\max }$ & $S_{\max }$ & $\mathrm{N}$ & $\mathrm{Cr}$ & Mo & $\mathrm{Ni}$ & $\mathrm{Fe}$ \\
\hline Steel grade 1.4462 & 0.030 & 0.614 & 1.779 & 0.029 & 0.001 & 0.178 & 22.8 & 3.33 & 4.8 & Bal. \\
\hline Steel grade 1.4462 & 0.030 & 0.614 & 1.779 & 0.029 & 0.001 & 0.178 & 22.8 & 3.33 & 4.8 & Bal. \\
\hline
\end{tabular}



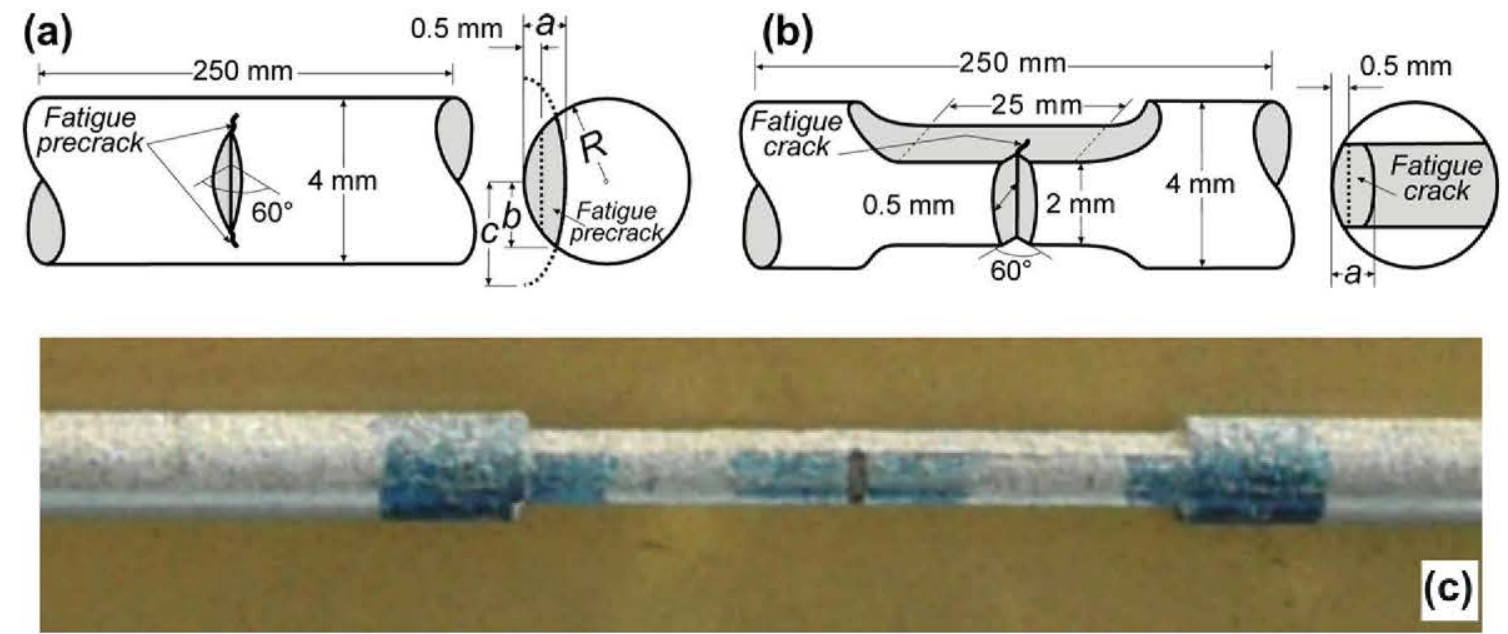

Fig. 2. (a) Wire specimen configuration for fracture tests showing the position dimensions of the notch used as fatigue precraking starter; (b) sketch of a flat specimen machined from the previously notched and fatigue pre-cracked wire specimen; (c) flat specimen prepared for VIC-2D monitoring.
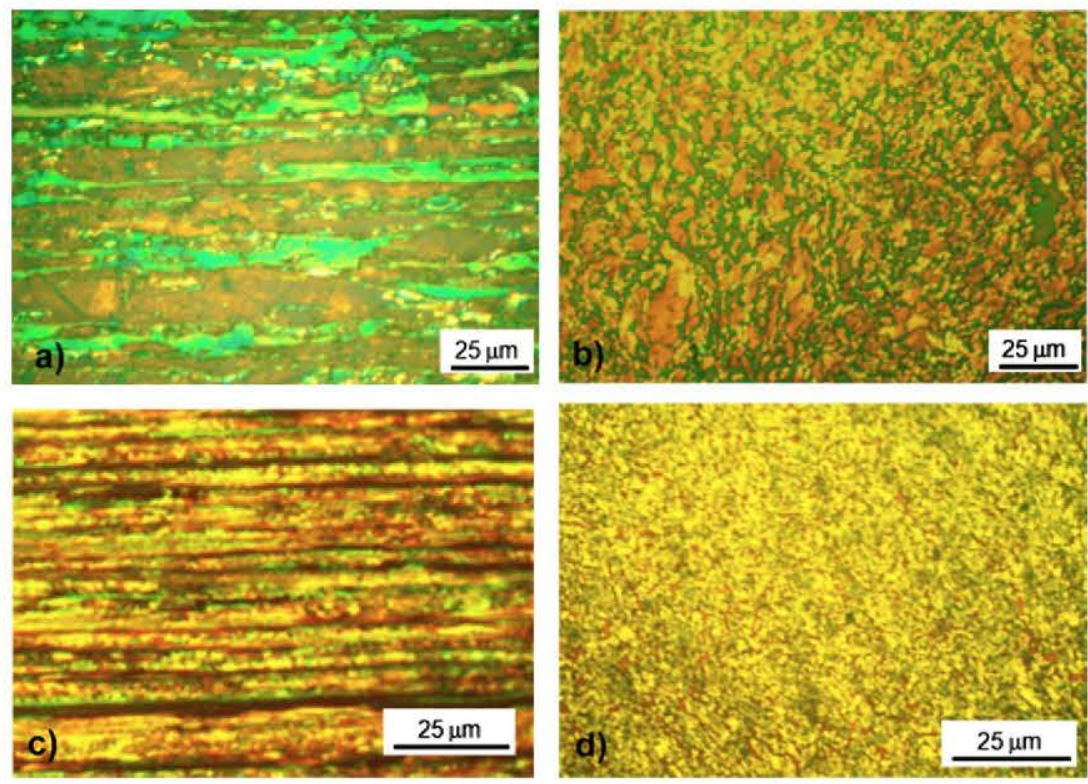

Fig. 3. Optical microstructures of the tested 1.4462 duplex steel: (a) along the drawing direction before cold drawing; (b) normal to the drawing direction before cold drawing; (c) along the drawing direction after cold drawing; (d) normal to the drawing direction after cold drawing.

Table 2

Mechanical properties of the 1.4462 steel grade wire and bar.

\begin{tabular}{llllll}
\hline 1.4462 Tested steel & $\begin{array}{l}\text { Elastic modulus, } E \\
(\mathrm{GPa})\end{array}$ & $\begin{array}{l}\text { Yield strength, } R_{p 0.2} \\
(\mathrm{MPa})\end{array}$ & $\begin{array}{l}\text { Tensile strength, } R_{m} \\
(\mathrm{MPa})\end{array}$ & $\begin{array}{l}\text { Maximum uniform elongation, } A_{5} \\
(\%)\end{array}$ & $\begin{array}{l}\text { Reduction of area } \\
(\%)\end{array}$ \\
\hline $\begin{array}{c}\text { Before cold drawing }(9 \mathrm{~mm} \\
\text { bar) }\end{array}$ & 160 & 680 & 870 & 17 & 83 \\
$\begin{array}{c}\text { After cold drawing }(4 \mathrm{~mm} \\
\text { wire) }\end{array}$ & 160 & 1420 & 1660 & 2.2 & 67 \\
\hline
\end{tabular}

cracked region [11,17]. The geometric parameters of the fatigue crack corresponding to b1-b9 specimens are presented in Table 3: the crack depth $a$ and the distance $2 b$ between the two crack front ends were measured by optical microscopy; than the ellipsis major semi-axis $c$ was computed from $a$ and $b$. These data are further used for the damage tolerance evaluation.

The anisotropic fracture behaviour of the 1.4462 steel grade wire is consistent with the metallographic analysis results which show that the microstructure is markedly oriented in the wire axis direction as a consequence of cold drawing. Fig. 6 gets an insight into the anisotropic fracture pattern of the wire, consisting of three distinct macroscopic regions: the first is the initial fatigue crack propagation in mode I (Fig. 6a), the second is a deflected crack extension along the wire axis (Fig. 6b), and the third is the final shear face ductile fracture which breaks the wire by overload, after necking (Fig. 6c). As shown in Fig. 6a, what failed by necking was the remaining uncracked ligament of the wire after the deflected crack extension. The deflection occurs at $90^{\circ}$ with respect to the fa- 


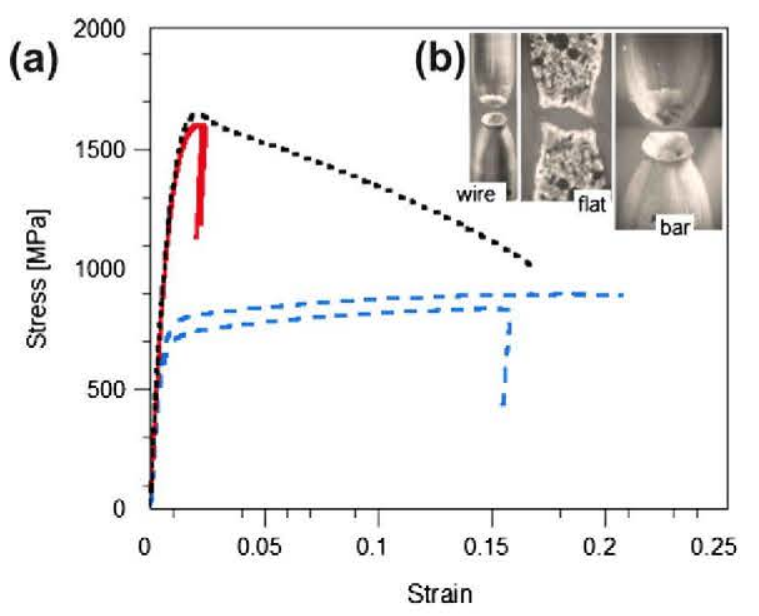

-. Before cold drawing (9 mm Bar)

- After cold drawing (4 mm Wire)

..... After cold drawing (2 mm thick Flat Specimen)

Fig. 4. (a) Engineering stress-strain curves of the 1.4462 steel before cold drawing (as $9 \mathrm{~mm}$ bar) and after cold drawing (as $4 \mathrm{~mm}$ wire and $2 \mathrm{~mm}$ thick flat specimen); (b) tensile necking and fracture mode of the specimens.

tigue crack due to the anisotropy of the cold-drawn material. Once the stress field at the crack front becomes critical, the fracture propagates and arrests along the wire longitudinal axis due to the weakness of the material planes parallel to this direction. Details of wire decohesion at longitudinal "stringers" of the drawing texture are presented in Fig. 6c. The posterior increase of the tensile load is no longer producing crack extension, but it accelerates the plastic flow of the uncracked ligament until plastic instability and necking are activated. The final failure occurs by overload and it consists of a ductile rupture on an inclined plane, characterised by elongated shear dimples, as shown in Fig. 6d-f.

According to Fig. 5b, the fatigue crack size influences the length of the deflected crack extension and the subsequent necking which produces the wire failure. A similar effect is noticed on the loaddisplacement curves of the b1-b9 specimens, which show how the maximum and failure loads, as well as failure displacement, depend on the crack size (Fig. 7). In all cases, the load increases gradually up to a maximum, but no sign reveals the exact moment of longitudinal crack extension and arrest. However, an insight into this process was obtained by using the VIC-2D technique for monitoring the fracture behaviour of plane specimens extracted from cylindrical specimens previously cracked by fatigue, as shown in Fig. 2.

Fig. 8a shows the load-displacement curve of the fracture test of a fatigue pre-cracked flat specimen whose elongation was measured with a "virtual extensometer" provided by the VIC-2D system. Nine relevant points to the fracture process appear labelled as a1-a9 in Fig. 8a. Fig 8b is a detail showing the gauge length of the virtual extensometer. Fig. $8 \mathrm{~d}$ presents the images of the crack at the instants of the points a1-a9, as acquired with the VIC-2D system. This sequence of images illustrates main the events of the failure process; first, in the linear part of the load-displacement curve (a1-a2) the fatigue crack tip slightly blunts as tensile load increases; the subsequent deviation from linearity indicates that general yielding of the cracked region occurs with the consequent acceleration of blunting, which is not accompanied by any visible ductile tearing (a3). On the contrary, the extension and arrest of the crack along the wire axis roughly occurs at the instant the point a 4 is attained. Beyond this point the remaining uncracked ligament starts elongating and the faces of the fatigue crack displaces one from each other (a4-a5). At maximum load (image a6) the instable plastic flow accompanied by necking initiates at the uncracked ligament. This constrained necking continues, as shown in images a7 and a8, until final failure takes place (a9) and the remaining ligament brakes by shearing on an inclined plane (Fig. 8c).

The common features of fracture process in the two specimens' configurations confirm that the anisotropy induced by cold-drawing is the leading element of fracture. VIC-2D analysis proves that the stress concentration produced by the tensile load at the fatigue crack front discharges along the cold-drawn material planes of weakness. Their orientation along the wire axis produces crack extension and arrest parallel to the longitudinal direction of the wire before reaching maximum load. Thus, the catastrophic failure of the wire is due to plastic instability and necking of the uncracked ligament.

\subsection{Damage tolerance}

\subsubsection{Experimental results}

The above presented fracture tests provide a quantitative empirical measurement of the damage tolerance of the cold drawn wire of 1.4462 steel grade. The damage tolerance curve is the experimental tensile bearing capacity of the cracked wires, i.e. the maximum tensile load $P_{Y}$ given as a function of crack size, expressed as the crack depth, $a$. As shown in Fig. 9 the experimental

(a)

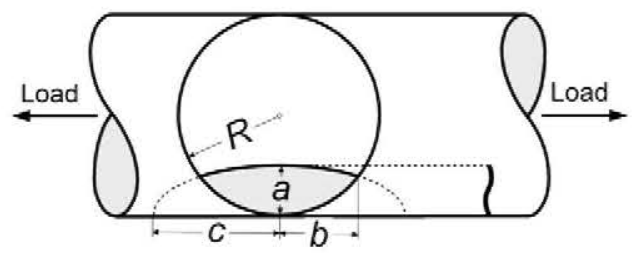

(b)
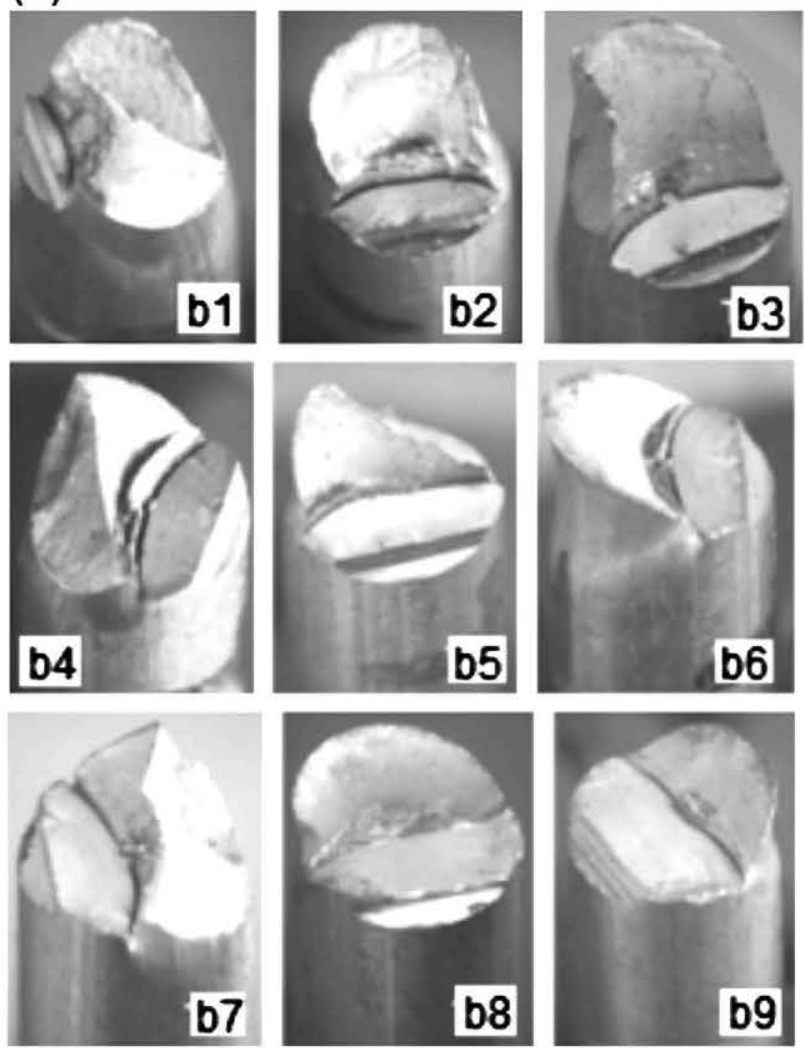

Fig. 5. (a) Semi-elliptical crack configuration; (b) images capturing the wire specimenś failure after their previous fatigue cracking. 
Table 3

Fatigue crack parameters resulted from direct measurements on different wire specimens' fracture surface.

\begin{tabular}{|c|c|c|c|c|c|c|c|c|c|}
\hline \multirow[t]{2}{*}{ Fatigue crack dimensions } & \multicolumn{9}{|c|}{ Specimen (according to Fig. 5 notations) } \\
\hline & $b 1$ & $b 2$ & $b 3$ & $b 4$ & $b 5$ & $b 6$ & b7 & $b 8$ & $b 9$ \\
\hline$a$ - Crack depth (mm) & 0.85 & 1.39 & 1.57 & 1.67 & 1.69 & 1.74 & 1.79 & 2.28 & 2.32 \\
\hline $2 b$ - Distance between crack front ends ( $\mathrm{mm}$ ) & 2.42 & 3.29 & 3.29 & 3.52 & 3.72 & 3.59 & 3.63 & 3.88 & 3.96 \\
\hline$a / c-$ Crack aspect ratio & 0.62 & 0.66 & 0.77 & 0.79 & 0.59 & 0.74 & 0.75 & 0.88 & 0.79 \\
\hline
\end{tabular}

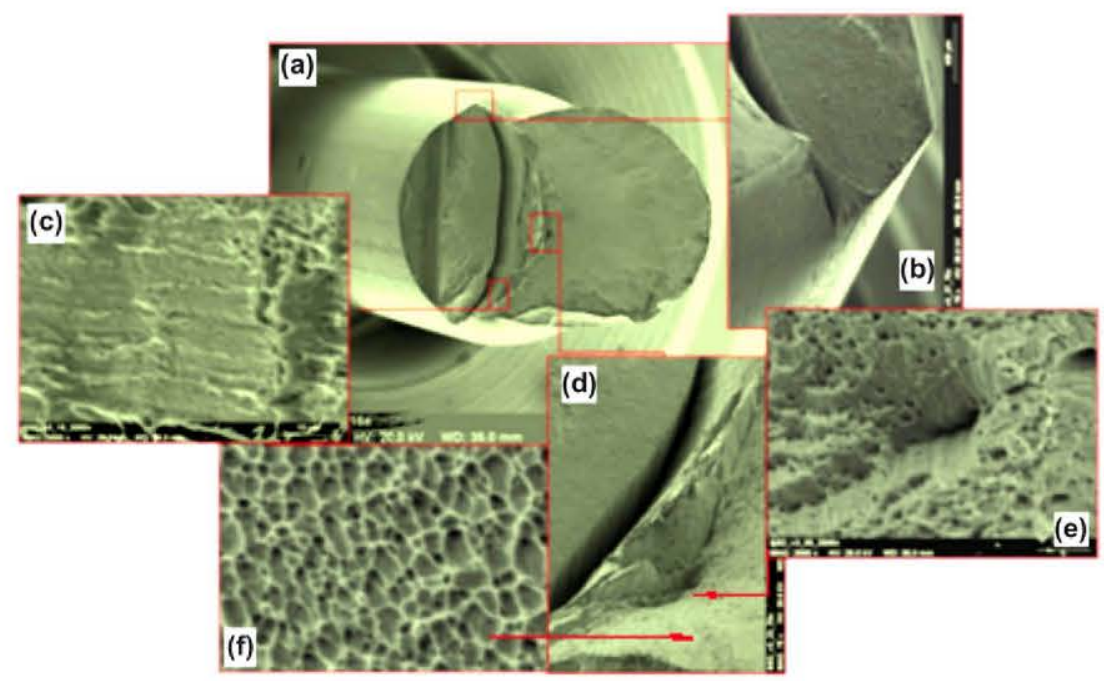

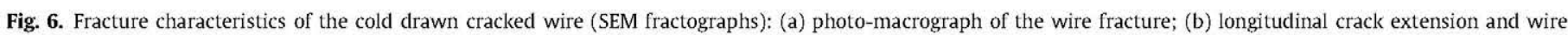

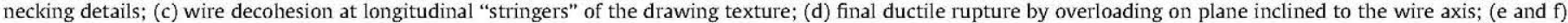
elongated and open shear dimples at the final ductile rupture.

values are plotted in dimensionless terms, by using the wire radius $R$ and the tensile bearing capacity $P_{0}$ of the undamaged wire as units of the abscissa and ordinate axis, respectively. The significance of the damage tolerance, as shown in Fig. 9, cannot be fully assessed unless compared with that of similar materials or with a theoretical model prediction.

\subsubsection{Damage tolerance assessment}

An elementary uniaxial plastic collapse model for a cracked wire in tension [10] is used for a first assessment of the damage tolerance data of the tested cold-drawn 1.4462 steel grade wire. According to the model, the plastic collapse stress distribution at the cracked cross section is that shown in Fig. 10a. The material is assumed to be perfectly plastic and its yield stress, $\sigma_{y}$, is identified with the tensile strength of the tested material. Usually, the mean value between the yield and tensile strengths is used for the plastic limit load calculus, but tensile strength provides a more demanding damage tolerance reference. Generally, the plastic collapse load $P_{Y}$, is given by:

$P_{Y}=\pi R^{2} \sigma_{y} f\left(\frac{a}{R}, \frac{a}{c}\right)$

where the function $f(\cdot)$ results from the forces and moments equilibrium between the applied load and the stresses acting on the cracked cross-section. The unknowns to be found out from the two resulting equations are the load $P_{Y}$ and the distance $x$ that defines the position of the separation line between the tensioned and compressed parts of the cracked cross-section (Fig. 10a). The equations can be numerically solved with the aid of a spreadsheet application, but integrals over the tensioned and compressed parts are involved and a no closed-form of the function $f(\cdot)$ is obtained. Fig. $10 \mathrm{~b}$ shows the plot of the function for a number of crack aspect ratios ranging from straight $(a / c=0)$ to almost circular crack front $(a / c=0.8)$; also plotted are the $f(\cdot)$ values when the crack aspect ratio varies as a function of the relative crack depth $a / R$, according to the correlation of $a / R$ and $a / c$ found from the fatigue precracking experimental data.

The plastic collapse is an upper bound of the damage tolerance for the considered perfectly plastic wire. The region of the plane $a /$ $R-P_{Y} / P_{0}$ enclosed by Eq. (1) plots for $a / c=0$ and $a / c=0.8$ defines this upper bound of the cracked wires with crack fronts varying from straight to circular. As shown in Fig. 10b, the experimental damage tolerance of the tested cold-drawn 1.4462 steel wire

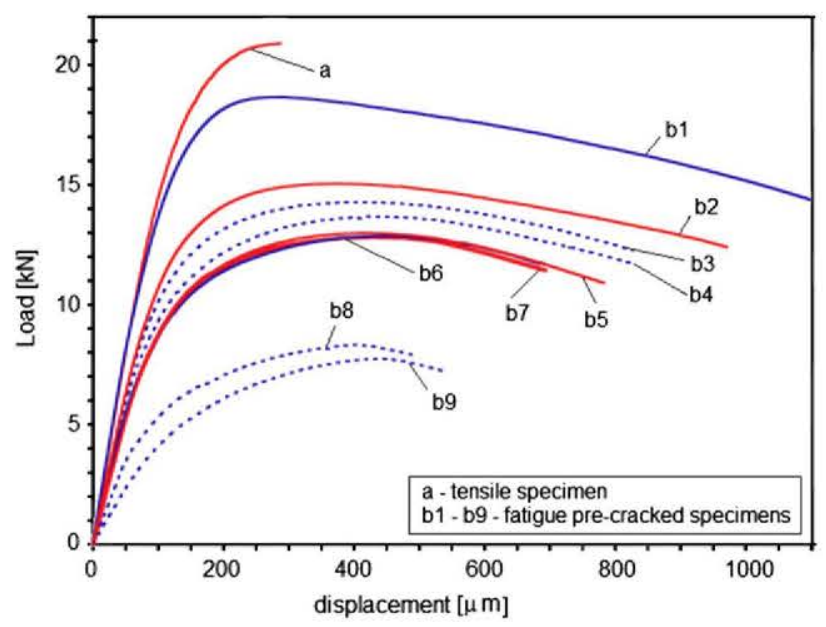

Fig. 7. Load-displacement curves of the fracture tests b1-b9, performed on cracked wires; the load-displacement curve of an un-cracked wire, a, is included for comparison. 


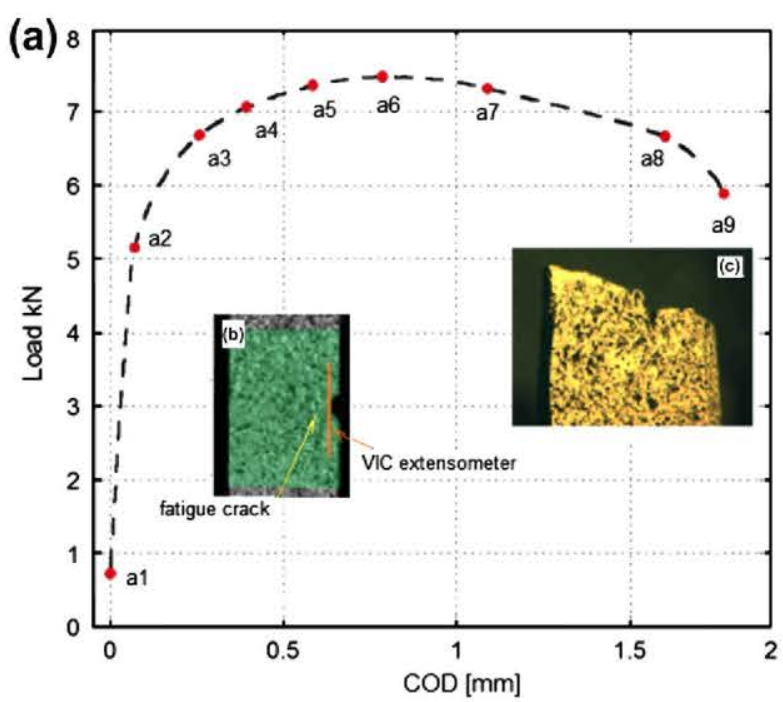

(d)
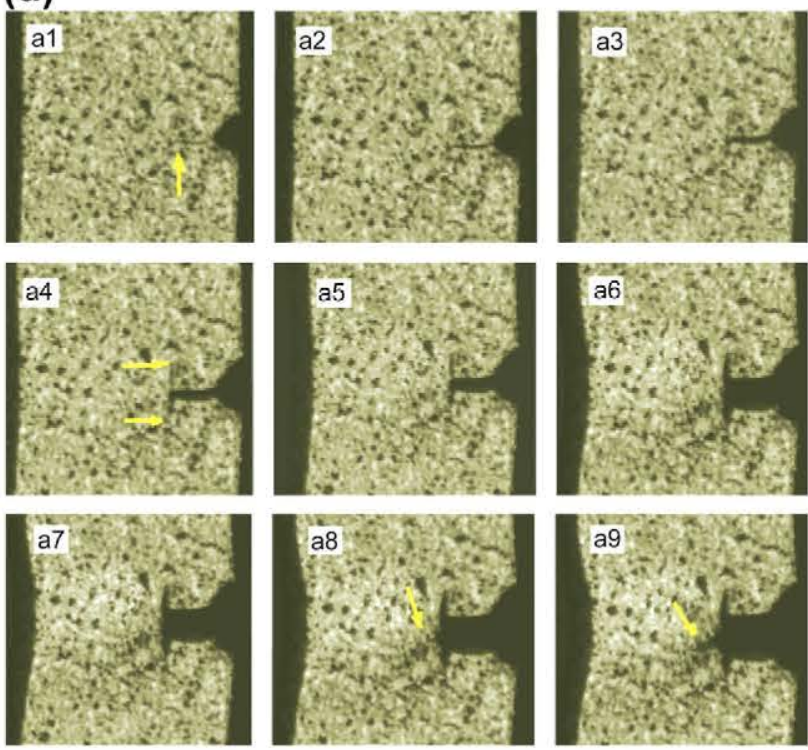

Fig. 8. Failure sequence of a fatigue pre-cracked flat specimen: (a) load-displacement curve indicating nine points relevant to failure, a1-a9; (b) gauge length of the VIC-2D virtual extensometer; (c) photo-macrograph of the fractured flat specimen; (d) images of the crack corresponding to a1-a9 points, as acquired with the VIC-2D system.

widely surpasses the upper bound resulting from identifying it with a perfectly plastic wire that yields beyond its tensile strength.

To complete the assessment of the damage tolerance of the tested cold-drawn steel wire a comparison with similar experimental data of two commercial eutectoid prestressing steels was found appropriate (Fig. 11); the first is a $7 \mathrm{~mm}$ diameter wire whose strength is obtained by cold drawing a hot rolled product, whereas the second is a hot rolled $9 \mathrm{~mm}$ diameter wire hardened

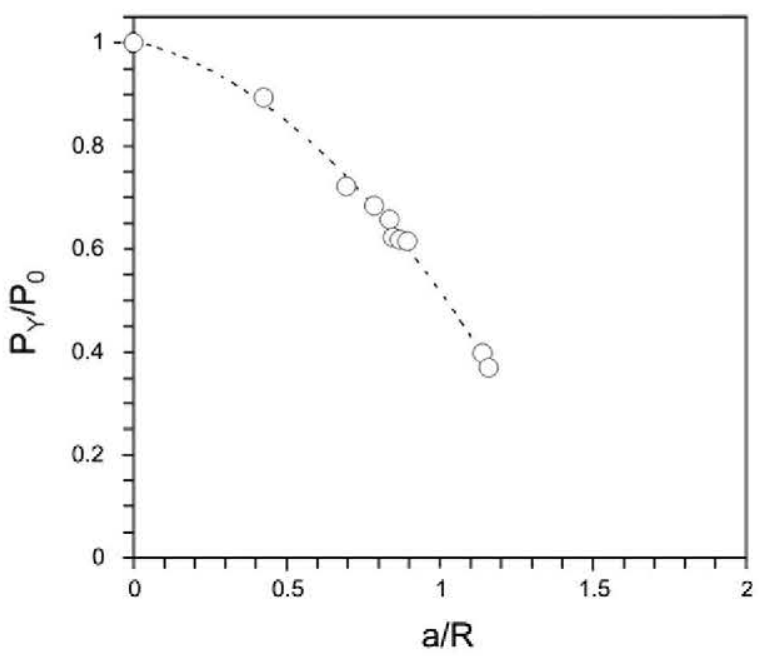

Fig. 9. Experimental damage tolerance of the tested cold-drawn 1.4462 steel wire.

(a)
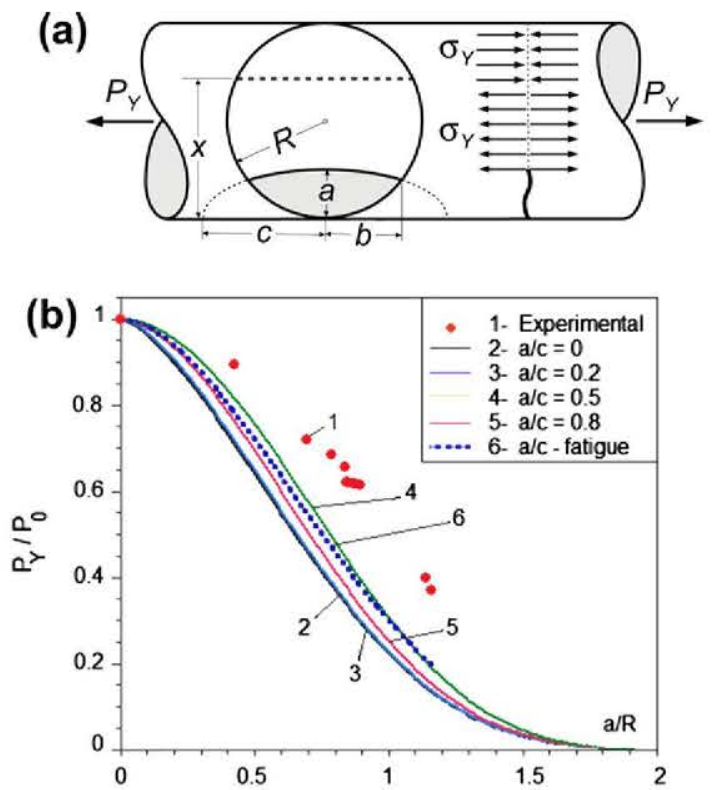

Fig. 10. (a) Stress distribution at plastic collapse in tension of a cracked, perfect plastic wire; (b) damage tolerance of the tested cold drawn 1.4462 steel wire vs. the upper bound of the perfect plastic wire.

by means of a heat treatment consisting of quenching and tempering. Table 4 resumes their mechanical properties which are comparable to the cold-drawn 1.4462 steel grade ones (Table 1 ) save the elongation, which is three times higher in case of the eutectoid steels.

As shown in Fig. 11, the damage tolerance of the eutectoid steels is high, and it agrees with the corresponding one computed with the theoretical model of plastic failure. Even though, the tested cold-drawn 1.4462 steel wire shows better damage toler-

Table 4

Mechanical properties of the two eutectoid prestressing steels.

\begin{tabular}{|c|c|c|c|c|c|}
\hline Eutectoid prestressing steel & $\begin{array}{l}\text { Elastic modulus, } E \\
(\mathrm{GPa})\end{array}$ & $\begin{array}{l}\text { Yield strength, } R_{p 0.2} \\
(\mathrm{MPa})\end{array}$ & $\begin{array}{l}\text { Tensile strength, } R_{m} \\
\text { (MPa) }\end{array}$ & $\begin{array}{l}\text { Maximum uniform elongation, } \\
A_{5}(\%)\end{array}$ & $\begin{array}{l}\text { Reduction of area } \\
(\%)\end{array}$ \\
\hline Cold-drawn $7 \mathrm{~mm}$ wire & 215 & 1460 & 1685 & 6.5 & 45 \\
\hline $\begin{array}{l}\text { Quenched and tempered } 9 \mathrm{~mm} \\
\text { wire }\end{array}$ & 210 & 1350 & 1470 & 6.5 & 46 \\
\hline
\end{tabular}




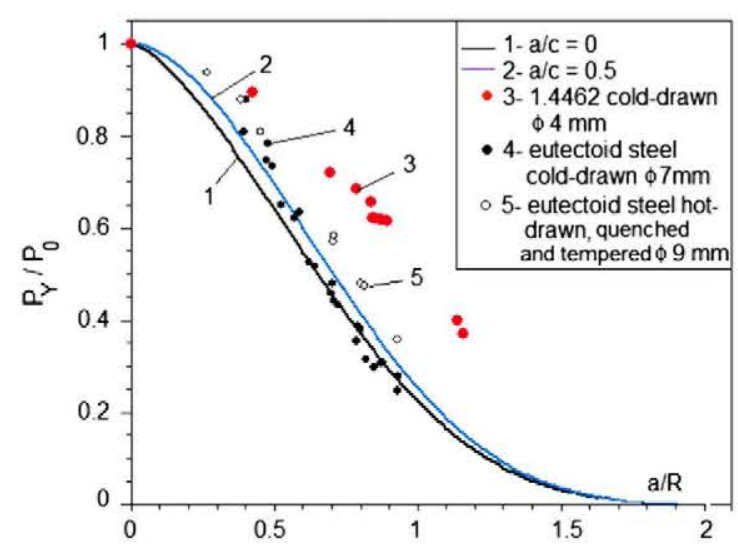

Fig. 11. Damage tolerance of the cold-drawn 1.4462 tested steel vs. those of two commercial eutectoid pre-stressing steels.

ance, the difference being the greater the more severe damage is. This result is in contrast to the scarce ductility attributable to the cold-drawn steel wire according to its maximum uniform elongation, which is markedly less than those of the two eutectoid prestressing steels. Consequently, the maximum uniform elongation cannot be understood as a necessary damage tolerance indicator.

\section{Conclusions}

The damage tolerance of a cold-drawn 1.4462 steel grade wire was empirically found by tensile testing fatigue cracked wires up to fracture. The measured failure loads shows that cold drawing is endowing the 1.4462 steel with tensile strength, comparable with that of prestressing steel, without inducing poor a damage tolerance. On the contrary, it surpasses that of a perfectly plastic wire and also those of two representative eutectoid prestressing steels.

The measured damage tolerance can characterise highly ductile steels, but this is in contrast to the low value of the maximum uniform elongation found during the wire testing. It results that the tested cold drawn steel wire is damage tolerant even though its maximum uniform elongation corresponds to a material of poor ductility.

The anisotropic fracture behaviour of the cold-drawn 1.4462 steel grade wire is consistent with the metallographic analysis results which show that the microstructure is markedly oriented in the wire axis direction as a consequence of cold drawing. VIC-2D analysis proved that tensile loading of the transverse cracked wire does not produces a catastrophic fracture; a deflected extension and arrest, along the wire axis, of the initial crack being firstly registered. Afterwards, the tensile failure of the wire occurs by plastic instability and necking of the uncracked ligament, which brakes by ductile shearing due to overload. Thus, the contribution of cold drawing induced anisotropy to this two-phase failure process is determinant to the exhibited damage tolerance.

\section{Acknowledgements}

The authors gratefully acknowledge the financial support of the Spanish Ministerio de Ciencia e Innovación through the Project BIA2008-06705-C02-01, the assistance of Dr. Maria Cruz Alonso from Eduardo Torroja - Institute of Construction Sciences, CSIC, Spain, and the collaboration with INOXFIL S.A. who kindly provided the cold-drawn 1.4462 steel grade.

\section{References}

[1] Badoo NR. Stainless steel in construction: a review of research, applications, challenges and opportunities. J Constr Steel Res 2008;64(11): 1199-206.

[2] Gedge G. Structural uses of stainless steel - buildings and civil engineering. J Constr Steel Res 2008;64(11):1194-8.

[3] Nurnberger U, Wu Y. Stainless steel in concrete structures and in the fastening technique. Mater Corros 2008;59(2):144-58.

[4] Pérez-Quiroz JT, Terán J, Herrera MJ, Martínez M, Genescá J. Assessment of stainless steel reinforcement for concrete structures rehabilitation. J Constr Steel Res 2008;64(11):1317-24.

[5] Wu Y, Nurnberger U. Corrosion-technical properties of high-strength stainless steels for the application in prestressed concrete structure. Mater Corros 2009;60(10):771-80

[6] Hedayati A, Najafizadeh A, Kermanpur A, Forouzan F. The effect of cold rolling regime on microstructure and mechanical properties of AISI 304L stainless steel. J Mater Process Technol 2010;210:1017-22.

[7] Ravi Kumar B, Sharma S, Mahato B. Formation of ultrafine grained microstructure in the austenitic stainless steel and its impact on tensile properties. Mater Sci Eng A - Struct 2011;528:2209-16.

[8] Milada M, Zreibaa N, Elhalouanib F, Baradaib C. The effect of cold work on structure and properties of AISI 304 stainless steel. J Mater Process Technol 2008;203:80-5.

[9] prEN 10138-2:2009, Prestressing steel - Part2: Wire, CEN, Brussels; 2009.

[10] Valiente A, Elices M. Premature failure of press-stressed steel bars. Eng Fail Anal 1998:5:219-27.

[11] Toribio J, Valiente A. Failure analysis of cold drawn eutectoid steel wires for prestressed concrete. Eng Fail Anal 2006;13:301-11.

[12] Toribio J, Valiente A. Approximate evaluation of directional toughness in heavily drawn pearlitic steels. Mater Lett 2004;58:3514-7.

[13] Jordachescu M, Valiente A, Caballero L, Iordachescu D, Porro JA, Ocaña JL. Laser shock processing influence on local properties and overall tensile behaviour of friction stir welded joints. Surf Coat Technol 2012;206(8-9):2422-9.

[14] EN 10088-3. Chemical composition of stainless steel; 2006.

[15] BS 6744. Chemical composition and mechanical properties of stainless steel; 2009 .

[16] ASM Handbook. Metallogr Microstruct 2004;9:525-542.

[17] Toribio J, Alvarez N, González B, Mateos JC. A critical review of stress intensity factors for surface cracks in round bars subjected to tension loading. Eng Fail Anal 2009; 16:794-809. 